\title{
Development of a saphenous vein harvest model for simulation-based assessment
}

\author{
Melissa C. Duffy, PhD, ${ }^{a}$ Marina Ibrahim, MD, MSc, ${ }^{b}$ and Kevin Lachapelle, MD, FRCSC, FACS ${ }^{b, c}$
}

\section{ABSTRACT}

Objective: There is a need to develop a realistic model of open saphenous vein harvesting for simulation training and assessment. The purpose of this study was to develop a novel simulated model of this procedure and to examine its viability by examining participants' performance and feedback on this model.

Methods: A total of 14 participants (cardiac surgeons, residents, students) conducted open saphenous vein harvesting on a portable, noncommercial, simulated vein model (complete with artificial vein, subcutaneous tissue, and skin) within an operating room. Surgical assistance was provided by a cardiac resident. Participants provided feedback through questionnaires and interviews. Technical performance was rated by 2 blinded raters using a global rating scale for operative technical skills.

Results: Quantitative analyses demonstrated that participants considered the model to be realistic and useful. Analyses of performance ratings indicated that the model could be used as a reliable indicator of skill level, given that raters were able to use performance scores to discriminate participants according to their level of experience at a high level of accuracy. Participants with a higher level of experience performed significantly better than those with a lower level of experience. Qualitative analyses revealed the model was considered to be most beneficial to learn procedural steps of vein harvesting and basic surgical skills.

Conclusions: Results provide support for the technical fidelity of this model and its ability to identify skill level for assessment of vein harvesting. Future work should examine transfer of surgical skills from simulator to clinical practice to assess its viability for training. (J Thorac Cardiovasc Surg 2019;157:1082-9)

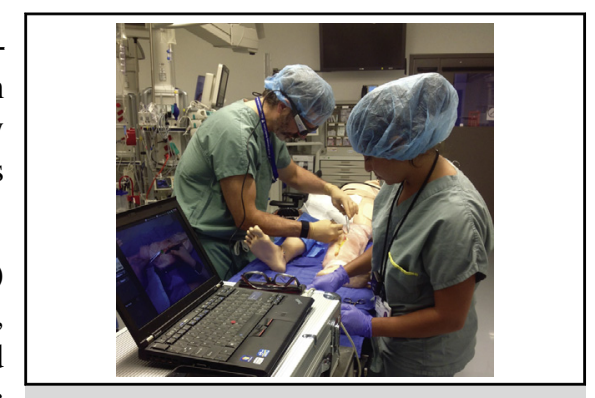

The vein harvest simulation.

\section{Central Message}

This study provides support for the utility of a novel vein harvest model. The model could be used to assess trainees' competence before conducting the procedure in the OR.

\section{Perspective}

There has yet to be a simulation model created specifically for the open saphenous harvesting procedure. We developed a portable simulation model. On the basis of initial evidence, we believe that the model could be used as a component of assessment.

See Commentary on page 1090.
Coronary artery bypass grafting (CABG) remains the standard of practice to treat severe cases ${ }^{1-3}$ of coronary artery disease and is one of the most commonly conducted operations ${ }^{4}$ frequently coupled with harvesting of the greater saphenous vein of the leg. ${ }^{5,6}$ In a conventional open vein harvest, ${ }^{7}$ the procedure involves

\footnotetext{
From the ${ }^{a}$ Department of Educational Studies, University of South Carolina, Columbia, SC; ${ }^{b}$ Division of Cardiac Surgery, McGill University, Montreal, Quebec, Canada; and ${ }^{\mathrm{c}}$ Steinberg Centre for Simulation and Interactive Learning, McGill University, Montreal, Quebec, Canada.

This research was supported by a Social Sciences and Humanities Research Council Grant (895-2011-1006).

The study was approved by the Institutional Review Board on October 28, 2013 (A10-E87-13B).

Received for publication Nov 29, 2017; revisions received June 13, 2018; accepted for publication July 2, 2018; available ahead of print Sept 6, 2018.

Address for reprints: Kevin Lachapelle, MD, FRCSC, FACS, Glen Campus-The Royal Victoria Hospital, 1001 Decarie Blvd, Block C, C05.1284, Montreal, Quebec, H4A 3J1, Canada (E-mail: kevin.lachapelle@mcgill.ca). $0022-5223 / \$ 36.00$

Copyright (c) 2018 by The American Association for Thoracic Surgery https://doi.org/10.1016/j.jtcvs.2018.07.042
}

identifying the location of the vein, making an incision, and exposing and freeing the vein by dissecting and removing connective tissue and clipping and tying side branches. Once the desired graft length is obtained, the vein is clamped and tied at one end and then distended by inserting a cannula and injecting a solution to preserve the vein and identify any perforations that require repair. The incision site is then closed using sutures. This procedure is commonly performed by junior trainees and helps them acquire technical skills, such as instrument handling, tissue dissection, knot-tying, and suturing. ${ }^{8}$ It is a procedure that requires meticulous technique both for the longevity of

Scanning this $\mathrm{QR}$ code will take you to a supplemental video for the article. 

Abbreviations and Acronyms
$\mathrm{CABG}=$ coronary artery bypass grafting
$\mathrm{IQR}=$ interquartile range
OR = operating room
OSATS $=$ Objective Structured Assessment of Technical Skill

the graft and to reduce saphenous harvest site complications. ${ }^{9-11}$

Although saphenous vein harvesting is a common procedure, we believe there is a need for an open simulation model for the following reasons: (1) Saphenous harvesting is increasingly performed by professional assistants using open or endoscopic technique. As such, trainees may have fewer opportunities to practice this skill, which is a fundamental training objective. (2) Open saphenous harvesting may have significant complications, such as blood loss, hematomas, and infection, which may be related to poor technique; consequently, there is a patient safety imperative to ensure minimal risk. (3) As training shifts toward competency-based education and evaluation, it would be valuable to have standardized simulated models to assess surgical skills.

Within cardiac surgery, trainees often participate in a series of simulations that provide exposure to common heart surgery procedures, such as aortic valve replacement and anastomosis. However, the conventional process of harvesting the saphenous vein is not commonly included in surgical simulation curriculum, perhaps in part because procedures involving laparoscopic and endovascular simulators have attracted greater attention in simulation training than open surgical procedures. ${ }^{12,13}$ More importantly, the lack of a viable model has likely reduced opportunities for incorporating the open vein harvest into simulation, despite needs assessment results indicating that cardiothoracic faculty believe it would be helpful for surgical trainees to have exposure to this procedure through simulation. ${ }^{14}$

To address this gap, the purpose of the present study was to develop and assess the viability of a portable, easily constructed, noncommercial model for the open saphenous vein harvest procedure. More specifically, we examined the following: (1) participants' self-reported proficiency and confidence before and after using the model; (2) alignment between participant performance on the simulator and level of clinical experience; and (3) participants' feedback about the fidelity and utility of the model to identify areas for further development and practical use. These sources of data provide initial evidence pertaining to the validity of this model. Validity is a concept that refers to the extent to which a scale or tool (eg, simulation model) accurately and consistently measures what it is designed to measure (ie, does the model provide a meaningful simulation of the real-world procedure). ${ }^{15}$ This research provides an important step toward meaningful assessments of trainees' surgical skill in performing the open saphenous vein harvest.

\section{MATERIALS AND METHODS \\ Participants}

A convenience sample with 14 participants was recruited. The sample consisted of medical students $(\mathrm{N}=2)$, junior cardiac residents or residents on rotation in cardiac surgery $(\mathrm{N}=5)$, intermediate and senior cardiac residents $(\mathrm{N}=5)$, and cardiac staff surgeons $(\mathrm{N}=2)$. Medical students were in the final year or equivalent. Residents' years of training ranged from year 1 to 6 . The 2 cardiac surgeons had a range of 11 to 15 years of experience.

\section{Measures}

Prior experience scale. A Likert scale was used to measure the number of times the participant had previously observed and conducted the procedure in the operating room (OR) and simulation environment. Option choices included 0,1 to 5,6 to 10,11 to 15,16 to 20 , and 21 or greater. Given that this question required participants to estimate their prior experience, option choices included a range of times (categoric), rather than requesting a fixed number that may be more susceptible to error. In addition, an open-ended question was included asking participants to report relevant training. Participants were classified as high prior experience if they conducted the procedure in the OR more than 20 times before the simulation $(\mathrm{n}=8)$. The remaining participants were classified as low prior experience $(\mathrm{n}=6)$.

Self-efficacy scale. A single item adapted from Bandura's scale ${ }^{16}$ was used to measure participants' confidence (before and after the task) that they could effectively conduct the procedure. The item was phrased as follows: "Rate how confident you are that you can effectively conduct this surgical procedure." An 11-point Likert scale was used to rate confidence level ranging from 0 (no confidence) to 100 (complete confidence) using interval increments of 10 (eg, 0, 10, 20).

Proficiency scale. A single item was used to measure participants' self-assessed skill level (before and after the task) in vein harvesting. The item was phrased as follows: "Rate your level of proficiency in conducting this surgical procedure." A 5-point Likert scale was used to rate proficiency ranging from 1 (poor) to 5 (very good).

Simulation model feedback scale. A 2-item feedback scale was used to assess the realism and utility of the simulated vein model. The realism item was phrased as follows: "I found the simulator vein model realistic." The utility item was phrased as follows: "The vein model was useful for practicing my technique." A 5-point Likert scale was used to rate agreement ranging from 1 (strongly disagree) to 5 (strongly agree).

Technical skills performance. The Objective Structured Assessment of Technical Skill (OSATS) global rating scale ${ }^{17,18}$ contains 7 dimensions that measure the multifaceted nature of operative skill, including respect for tissue, time and motion, instrument handling, knowledge of instruments, flow of operation, use of assistants, and knowledge of specific procedure. For each item, anchored descriptions are provided for the lower end, midway point, and upper end of the 5-point Likert scale to operationally define skill level. For instance, the anchor for the lower end of time and motion item reads "many unnecessary moves"; the anchor for the upper end reads "clear economy of movement and maximum efficiency." The OSATS is appropriate when used for a specific procedure, such as the vein harvest. High levels of reliability and validity have been established for this assessment tool. ${ }^{18,19}$ The list of items and anchors is shown in Table 1. 
TABLE 1. Objective structured assessment of technical skill global rating scale of operative performance

\begin{tabular}{|c|c|c|c|}
\hline \multirow[b]{2}{*}{ Item } & \multicolumn{3}{|c|}{ Rating and anchor } \\
\hline & 1 & 2 & 5 \\
\hline Respect for tissue & $\begin{array}{l}\text { Frequently used unnecessary force on } \\
\text { tissue or caused damage by } \\
\text { inappropriate use of instruments }\end{array}$ & $\begin{array}{l}\text { Careful handling of tissue but } \\
\text { occasionally caused inadvertent } \\
\text { damage }\end{array}$ & $\begin{array}{l}\text { Consistently handled tissues } \\
\text { appropriately with minimal } \\
\text { damage }\end{array}$ \\
\hline Time and motion & Many unnecessary moves & $\begin{array}{l}\text { Efficient time/motion but some } \\
\text { unnecessary moves }\end{array}$ & $\begin{array}{l}\text { Clear economy of movement and } \\
\text { maximum efficiency }\end{array}$ \\
\hline Instrument handling & $\begin{array}{l}\text { Repeatedly makes tentative or } \\
\text { awkward moves with instruments } \\
\text { by inappropriate use of instruments }\end{array}$ & $\begin{array}{l}\text { Competent use of instruments but } \\
\text { occasionally appeared stiff or } \\
\text { awkward }\end{array}$ & $\begin{array}{l}\text { Fluid moves with instruments and no } \\
\text { awkwardness }\end{array}$ \\
\hline Knowledge of instrument & $\begin{array}{l}\text { Frequently asked for wrong } \\
\text { instrument or used inappropriate } \\
\text { instrument }\end{array}$ & $\begin{array}{l}\text { Knew names of most instruments and } \\
\text { used appropriate instrument }\end{array}$ & $\begin{array}{l}\text { Obviously familiar with the } \\
\text { instruments and their names }\end{array}$ \\
\hline Flow of operation & $\begin{array}{l}\text { Frequently stopped operating and } \\
\text { seemed unsure of next move }\end{array}$ & $\begin{array}{l}\text { Demonstrated some forward planning } \\
\text { with reasonable progression of } \\
\text { procedure }\end{array}$ & $\begin{array}{l}\text { Obviously planned course of } \\
\text { operation with effortless flow from } \\
\text { one move to the next }\end{array}$ \\
\hline Use of assistants & $\begin{array}{l}\text { Consistently placed assistants poorly } \\
\text { or failed to use assistants }\end{array}$ & $\begin{array}{l}\text { Appropriate use of assistants most of } \\
\text { the time }\end{array}$ & $\begin{array}{l}\text { Strategically used assistants to the } \\
\text { best advantage at all times }\end{array}$ \\
\hline $\begin{array}{l}\text { Knowledge of specific } \\
\text { procedure }\end{array}$ & $\begin{array}{l}\text { Deficient knowledge. Needed specific } \\
\text { instruction at most steps }\end{array}$ & Knew all important steps of operation & $\begin{array}{l}\text { Demonstrated familiarity with all } \\
\text { aspects of operation }\end{array}$ \\
\hline
\end{tabular}

\section{Simulation Model}

The saphenous vein model was designed to simulate vessel dissection, side branch ligation, and saphenous vein vessel harvesting. All vein models were developed at a medical simulation center by a cardiac resident and surgical skills coordinator and transported to a hospital site. Each model consisted of synthetic gel-filled saphenous vein and branches, which were cushioned in simulated connective tissue, subcutaneous fat, and a layer of skin (Figure 1). The model was designed to replicate the anatomy of the saphenous vein in the human leg and to closely approximate the subcutaneous tissues in a human using a gelatinous substance. The manufacturing process (Video 1) involved attaching 3 squares $(12 \times 12 \mathrm{~cm})$ of discarded artificial skin from TraumaMan (SimLab Corp, Santa Margarita, Calif) to simulate human skin. Empty rubber vein models were used (measuring $\sim 50 \mathrm{~cm}$ in length), colored gel was placed inside to simulate blood, and 6 side branches were anastomosed to each vein model. The branched vein model was then placed within the layers of the insert. The manufacturing process took approximately 2 hours per model. Each model was designed for single use. The model is estimated to cost approximately $\$ 150$ (time to construct the vein).

The model was attached to the leg of a mannequin (simulated patient), which was draped and placed on an operating table in the OR to heighten realism (Figure 2). Surgical instruments were available. Participants were instructed that they would be conducting the vein harvest procedure using the simulated vein model (1-time use as the model could not be reused once dissected and sutured). Participants conducted a saphenous vein harvest procedure within an OR that contained all equipment and instruments. The steps involved identifying the location of the vein (anterior edge of the medial malleolus), making the skin incision, exposing and dissecting

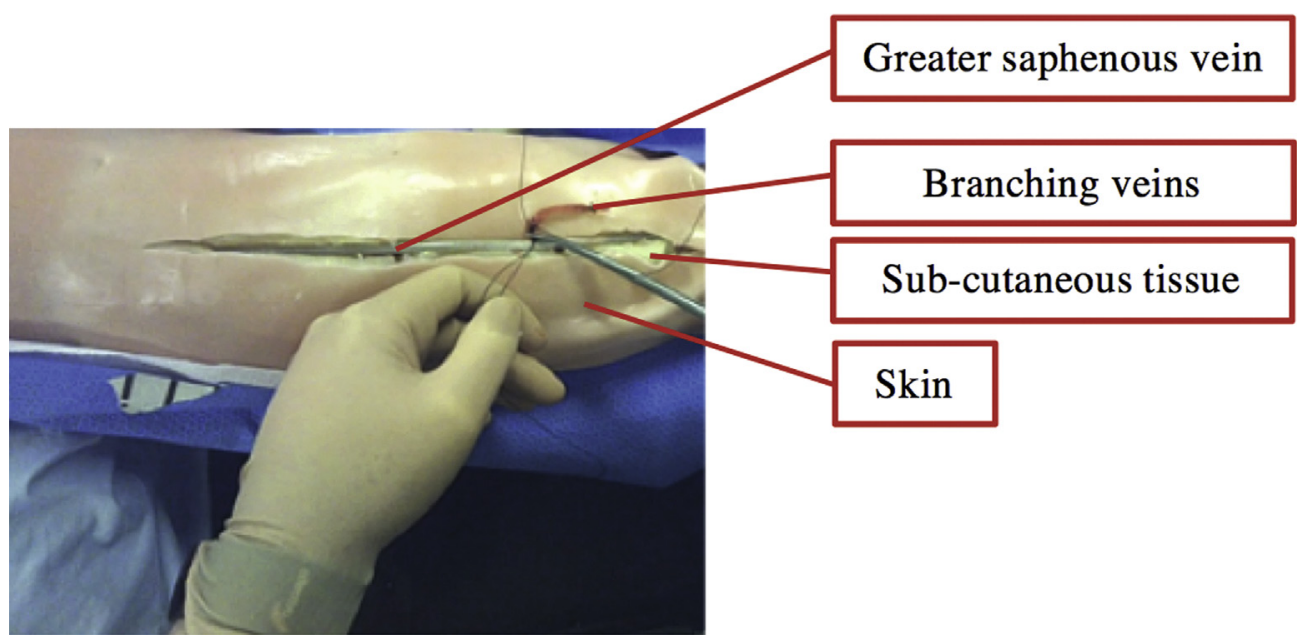

FIGURE 1. Saphenous vein model. 


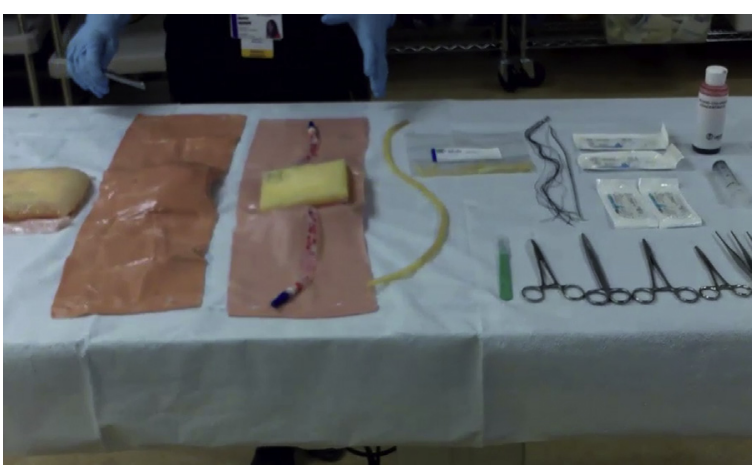

VIDEO 1. Dr Marina Ibrahim demonstrates the construction of the simulation model. Video available at: https://www.jtcvs.org/article/ S0022-5223(18)32020-8/fulltext.

the vein, tying off side branches, cannulating the vein proximally and freeing it from the wound, and finally skin closure. A cardiac resident was present to provide surgical assistance or instructional aid as needed. Similar to a real case in the OR, supervision and direction for the task were provided to varying degrees according to the participant's skill and experience level. All participants were given the same instructions regarding the goal and the steps of the procedure, including surgical landmarks. For novice learners, review was given on general use of instruments as needed so that they could perform the procedure. For intermediate and advanced learners, the main direction was to encourage and highlight to the participant to treat the simulated exercise as a real harvest.

\section{Procedure}

Ethics approval for this research was granted by the Institutional Review Board. A staff surgeon and cardiac resident identified potential participants currently on rotation in the cardiac unit, as well as dates for scheduling the simulation based on participant availability. After meeting the potential participant, the experimenter explained the purpose and protocol of the study, invited questions, and obtained signed consent. Participation was voluntary, and participants could withdraw participation at any time. The participant was oriented toward the simulation and completed a series of questionnaires before the procedure (demographics, self-efficacy, proficiency). An eye-tracking device was fitted to the participant to record videos of the procedure (reviewed afterward to assess technical performance). The experimenter was also present in the OR to take notes and time-stamps of the surgical procedure. After the procedure, the participant completed a series of questionnaires (self-efficacy, proficiency, simulation model feedback). After completion of these questionnaires, an interview was conducted. Questions included the following: "What was your impression of the model overall? Which aspects of the model did you find realistic? Which aspects of the model could be improved or were unrealistic? What or who do you think the model is most useful for?" A tablet was used to record questionnaire and interview responses. Interview recordings were transcribed verbatim and coded for themes related to the simulation experience and perceptions of the vein model based on responses to questions described.

\section{Technical Performance Ratings}

Two raters (a surgeon and a resident) independently assessed videos obtained from eye-tracking recordings (ie, scene view recordings) to assess technical skill performance for each participant using the OSATS global rating scale. ${ }^{15,16}$ Raters were blind to experience level and identification of participants. To establish consistency between raters, an expert and novice video was selected beforehand. Raters viewed and independently assessed technical skills for these participants before moving forward with the remaining sample. Discrepancies in these initial ratings were identified and resolved by discussing the rationale for decision-making. It was agreed that the upper range would represent high performance, whereas the lower range would represent low performance. The midway point represented standard vein extraction. Samples of key components of the surgical procedure (eg, initial incision, dissection/extraction, tying branches, cannulation, sutures, knot-tying) were viewed by each rater until they were satisfied they had reviewed sufficient video content to make an informed assessment. The use of video recordings to assess performance post hoc has been found to be both efficient and reliable in previous research. ${ }^{20}$

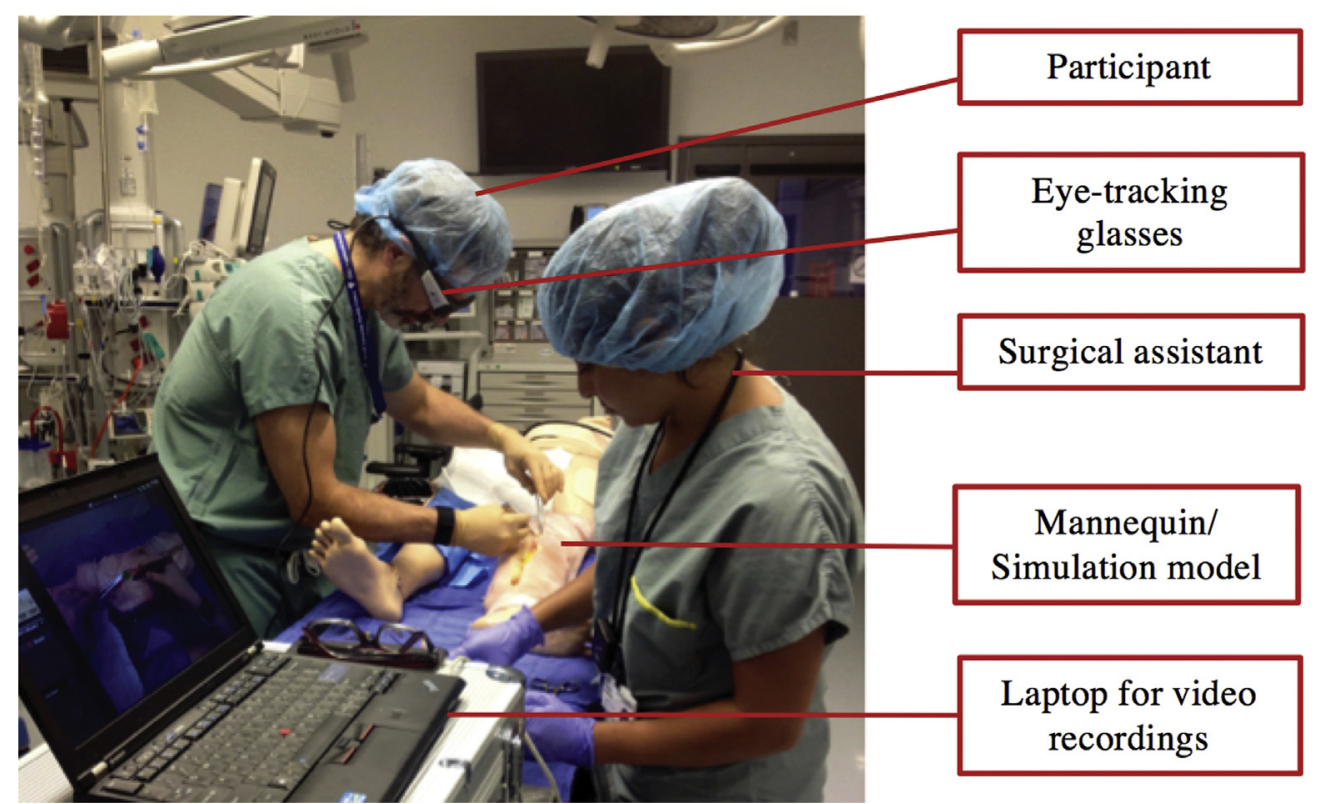

FIGURE 2. Experimental and surgical set-up of simulation. 
TABLE 2. Alignment between participant experience level and simulator performance scores

\begin{tabular}{llll}
\hline Participant $(\mathbf{N}=\mathbf{1 4})$ & Experience level (high vs low) & Performance level (mod-high vs low) & Correct classification \\
\hline 1 & High & 60 (mod-high) & Consistent \\
\hline 2 & High & 60 (mod-high) & Consistent \\
\hline 3 & High & 60 (mod-high) & Consistent \\
\hline 4 & High & 54 (mod-high) & Consistent \\
\hline 5 & High & 53 (mod-high) & Consistent \\
\hline 6 & High & 50 (mod-high) & Consistent \\
\hline 7 & High & 41 (mod-high) & Consistent \\
\hline 8 & High & 40 (mod-high) & Consistent \\
\hline 9 & Low & 52 (mod-high) & Inconsistent \\
10 & Low & 31 (low) & Consistent \\
\hline 11 & Low & 29 (low) & Consistent \\
12 & Low & 28 (low) & Consistent \\
13 & Low & 18 (low) & Consistent \\
\hline 14 & Low & 17 (low) & Consistent \\
\hline
\end{tabular}

Performance scores were calculated on the basis of a summed score of the 7 items on the OSATS global rating scale (each item scored on 1-5 scale) across 2 raters (maximum score of 70). Performance scores from 34 to 70 were classified as moderate-high; scores below 34 were classified as low. Correct classification indicates correspondence between (1) moderate-high score and higher experience level or (2) low score and lower experience level. Experience level was determined according to the number of times the participant previously conducted the procedure.

\section{Statistical Analysis}

Descriptive statistics were conducted for questionnaire items. Internal consistency of the OSATS global rating scale was conducted using Cronbach's alpha for inter-item reliability. Inter-rater reliability was conducted using an intraclass correlation on mean OSATS scores (2-way random consistency using average measures). ${ }^{21,22}$ Composite scores of performance were calculated for each participant using the summed ratings of the 7-item global rating scale (maximum score of 5 for each item), summed across the 2 raters (maximum score of 70). These composite scores were used as the technical skills performance variable in analyses. Participants' performance scores on the simulator were compared with their level of experience (prior experience conducting the procedure), which served as a comparative index of clinical skill level. As previously noted, participants were classified as high prior experience if they conducted the procedure more than 20 times and low prior experience if performed less than 20 times (this grouping represents relative rather than absolute expertise). ${ }^{23}$ To examine whether performance scores (high vs low) aligned with level of prior experience (high vs low) for each participant, consistencies between these groupings were totaled and a percentage was calculated. A Mann-Whitney $U$ test was conducted to test for differences in performance across experience level. An independent samples $t$ test was conducted to test for differences in efficiency (time) across levels of experience. Kolmogorov-Smirnov and Shapiro-Wilk tests of normality and Levene's tests of equality of variance were conducted to determine whether assumptions of normality and homogeneity of variance (across groups) were met for efficiency. Quantitative analyses were conducted using IBM (New York, NY) SPSS Statistics software (version 24)

\section{RESULTS \\ Quantitative}

The mean duration of simulation orientation and vein extraction was 13.1 minutes $( \pm 5.6)$ and 6.8 minutes for skin closure $( \pm 3.3)$. Descriptive statistics revealed that participants considered the model to be realistic (median,
4; interquartile range [IQR], 3-5) and useful for practicing technique (median, 4; IQR, 3.5-5). Participants with lower levels of prior experience reported an increase in self-efficacy from pre (median, 40; IQR, 17.5-82.5) to post (median, 60; IQR, 42.5-92.5) and an increase in proficiency from pre (median, 1.5; IQR, 1-4.25) to post (median, 3; IQR, 2.5-4) use of the simulator. Inter-rater reliability analysis revealed a high level of reliability between raters (intraclass correlation, 0.93). Internal consistency analysis revealed that the individual items of the OSATS scale were highly related to one another $(\alpha=0.97)$. Raters were able to discriminate participants' performance on the simulator consistent with prior experience (ie, aligned with level of clinical experience) at a high level of accuracy $(92.9 \%)$. Table 2 illustrates correspondence between simulator performance scores and

TABLE 3. Item-level performance by experience level

\begin{tabular}{lll}
\hline \multicolumn{1}{c}{ OSATS scale item } & \multicolumn{1}{c}{$\begin{array}{c}\text { High experience } \\
(\mathbf{n = 8})\end{array}$} & $\begin{array}{c}\text { Low experience } \\
(\mathbf{n = 6}=\mathbf{6})\end{array}$ \\
\hline Respect for tissue & $7.0(6.25-8.5)$ & $4.5(3.0-6.5)$ \\
Time and motion & $7.0(6.0-8.0)$ & $3.0(2.0-4.75)$ \\
\hline Instrument handling & $8.0(6.25-8.75)$ & $3.5(2.75-5.0)$ \\
Knowledge of instrument & $8.0(6.25-9.75)$ & $4.0(2.0-5.25)$ \\
Flow of operation & $7.5(6.0-8.0)$ & $4.5(2.0-5.5)$ \\
Use of assistants & $6.0(4.25-7.75)$ & $4.0(3.75-4.25)$ \\
Knowledge of specific procedure & $9.5(8.25-10.0)$ & $4.0(2.75-6.5)$ \\
\hline
\end{tabular}

OSATS, Objective Structured Assessment of Technical Skill. Performance scores for each item ranged from 2 to 10 (1-5 for each item of the OSATS global rating scale summed across 2 raters). Values denote median and IQR. 
TABLE 4. Results of qualitative content analysis of interviews

\begin{tabular}{|c|c|c|}
\hline Question & Category & Sample quotation \\
\hline \multirow{6}{*}{$\begin{array}{l}\text { What aspects of the model } \\
\text { were realistic? }\end{array}$} & Anatomy $(\mathrm{n}=8)$ & "The position of the vein was close anatomically to what we expect it to" \\
\hline & Tissue $(\mathrm{n}=5)$ & "I think the quality of the stuff you're using mimics some of the real tissues" \\
\hline & $\begin{array}{l}\text { Procedural steps/feeling } \\
\text { of procedure }(\mathrm{n}=3)\end{array}$ & "The steps, the process" \\
\hline & Suturing $(\mathrm{n}=1)$ & "I think the closing was good" \\
\hline & Instrument handling $(\mathrm{n}=1)$ & "How to handle the instruments" \\
\hline & Branches $(\mathrm{n}=1)$ & "[the] Branches" \\
\hline \multirow{5}{*}{$\begin{array}{l}\text { What aspects of the model } \\
\text { could be improved or } \\
\text { were unrealistic? }\end{array}$} & Branches $(\mathrm{n}=7)$ & "The branches were less realistic" \\
\hline & Tissue texture $(\mathrm{n}=6)$ & $\begin{array}{l}\text { "How the subcutaneous tissues can be; if it can be more dense then } \\
\text { we can put the sutures in it" }\end{array}$ \\
\hline & $\operatorname{Vein}(\mathrm{n}=5)$ & "The size of the vein is larger than the real-life" \\
\hline & Increase complexity $(n=4)$ & $\begin{array}{l}\text { There's less of the chaos that happens in the OR [real case] or the complexity... } \\
\text { that you don't have here" }\end{array}$ \\
\hline & Stability $(\mathrm{n}=1)$ & "It needs to be more stable" \\
\hline \multirow{8}{*}{$\begin{array}{l}\text { What or who do you think } \\
\text { this model is most } \\
\text { useful for? }\end{array}$} & Medical students $(\mathrm{n}=8)$ & "Medical student, basic surgical skills" \\
\hline & Junior residents $(\mathrm{n}=5)$ & "Junior residents. First and second year residents I think it would be a useful tool" \\
\hline & $\begin{array}{l}\text { Provides practice for those } \\
\text { with more experience }(n=3)\end{array}$ & $\begin{array}{l}\text { "For people that may have even had some experience with it, and want to look } \\
\text { at a more challenging procedure" }\end{array}$ \\
\hline & $\begin{array}{l}\text { Learning technical procedures/ } \\
\text { steps }(\mathrm{n}=4)\end{array}$ & "Vein harvesting... how to tie vascular" \\
\hline & Instrument handling $(\mathrm{n}=4)$ & "You can learn how to use the instruments while you're doing the dissection" \\
\hline & Tissue Handling $(\mathrm{n}=2)$ & $\begin{array}{l}\text { "Tissue handling skill because if you're rough than you're going to rip everything, } \\
\text { nothing is going to close." }\end{array}$ \\
\hline & $\begin{array}{l}\text { Troubleshooting/taking } \\
\text { time }(\mathrm{n}=2)\end{array}$ & $\begin{array}{l}\text { "In a real case it is time limited" } \\
\text { "for troubleshooting" }\end{array}$ \\
\hline & $\begin{array}{l}\text { Build confidence/stay } \\
\text { calm }(\mathrm{n}=2)\end{array}$ & $\begin{array}{l}\text { "What do you do if you encounter this, and you need a calm situation" } \\
\text { "this is what builds confidence" }\end{array}$ \\
\hline
\end{tabular}

OR, Operating room.

clinical experience level. A Mann-Whitney $U$ test revealed that participants with higher levels of prior experience demonstrated significantly higher performance scores on the simulator (median, 53.5; IQR, 43.25-60) compared with participants with lower levels of prior experience (median, 28.5; IQR, 17.75-36.25; $U=3.0, P<.01$ ). Table 3 illustrates performance scores for each component of the OSATS global rating scale. An independent samples $t$ test revealed that participants with higher levels of prior experience conducted the procedure (vein harvest excluding suturing) more efficiently $(7.6 \pm 2.5$ minutes) than those with lower levels experience of prior experience (13.8 \pm 3.5 minutes), $t(12)=3.9, P<.01$. The assumptions of normality and homogeneity of variance were met $(P>.05)$.

\section{Qualitative}

Content analysis of interview responses was conducted to identify prominent themes. Table 4 illustrates participant responses to interview questions. Frequencies were tallied for similar interview responses, which correspond to the key themes described here. Participants noted several aspects of the model that they considered to be realistic, including anatomy (positioning of the vein and tissues), tissue quality/feel, and procedural/technical steps. A common suggestion for improvement was to increase the number and quality of branching veins, because separating these from the greater saphenous vein can be one of the most time-intensive aspects of the procedure in a real case, requiring careful technique to control bleeding and prevent damage. Other suggestions included improving tissue 
quality (increasing density and stability for suturing), reducing vein size, and increasing complexity (suggested by more experienced participants). Regarding the utility of the simulation for training, most participants reported that it provided a useful opportunity for medical students and junior residents to improve basic surgical skills (suturing, knot-tying) and instrument handling, and to learn the technical steps involved in the vein harvest procedure. Participants also noted that the model could be useful for those with more experience to practice more complex techniques, improve efficiency, or prepare for more challenging aspects of the procedure (eg, handling fragile tissue). Finally, some participants noted that the simulation could help trainees to build confidence and prepare for real cases in the OR. In the following section, we discuss the implications of these results in terms of practical uses of the vein model.

\section{DISCUSSION}

The purpose of this research was to develop a simulated model of the vein harvesting procedure and assess its viability by examining (1) self-reported confidence and proficiency before and after using the model; (2) alignment between participant performance on the simulator and level of prior clinical experience; and (3) participants' feedback about the fidelity and utility of the model to identify areas for further development and practical use.

The results provide evidence supporting the technical fidelity of the model. Participants reported that the model was realistic and useful for practicing technique and improving skill. Raters were able to accurately discriminate participants with greater clinical experience from those with less clinical experience using performance scores on the simulation model. Participants with greater clinical experience performed significantly better and more efficiently than those with less experience, which indicates the model provides a reasonable representation of the real-life procedure. These findings are consistent with previous research that has demonstrated other cardiac simulation models (eg, off-pump CABG, coronary anastomosis, mitral valve surgery) are typically perceived as useful and can be reliably assessed by raters to detect differences in performance corresponding to experience level. ${ }^{24-28}$ Areas for development include enhancing psychologic fidelity $^{29}$ for more experienced participants by increasing the complexity of the procedure (eg, number of branches, time pressure) and simulating team dynamics that more closely approximate interactions in the OR that are likely to occur during this procedure.

One potential outcome is that the simulation model could be used to assess skill level/competencies ${ }^{30}$ for open vein harvesting before conducting the procedure for a real case in the OR. This may help to identify trainees that require additional training and help to reduce complications that arise from errors in the OR. As a portable device, the model can be transported inside or outside of hospital settings. This model also could be used in future research to more closely examine the learning trajectory for this procedure (eg, identifying benchmarks or milestones for competencies). The model may be useful for surgical training (eg, teaching procedural to novices, increase efficiency for experts). However, the viability of using this tool for skill development requires further investigation.

\section{Study Limitations}

There are several limitations of this study to note. First, the study included a small convenience sample. Second, the study did not examine skill acquisition or the transfer of skills from the simulation to clinical practice, and instead used a 1-time assessment. Third, we did not measure patient outcomes for participants who had used the model. Finally, we did not compare this model with other techniques used to teach this procedure. Future research should conduct a randomized control trial to compare the impact of training with the simulator to standard OR training and to examine transfer of surgical skills from the simulator to clinical practice. With a larger sample size, analyses could be conducted to assess how the simulator impacts aspects of learning and performance beyond immediate participant feedback (eg, retention of knowledge and skills). A larger sample size would also allow comparisons of skill level as determined on the model with measures of patient outcome, such as wound infection, hematoma, swelling, and pain. Feedback from a broader sample of surgeons could provide a more comprehensive assessment of the realism of this model. ${ }^{31}$ Finally, the use of 3-dimensional printing technology may help to facilitate broader distribution of this simulator and reduce costs associated with human resources in production.

\section{CONCLUSIONS}

Vein harvesting is an important component of CABG. However, to our knowledge, vein models have not yet been created to simulate open vein harvesting procedures for training or assessment purposes. Junior residents are often expected to conduct this procedure; however, their exposure is often limited to observation and guided instruction in the OR. The simulation model we developed provides a tool, which at this stage, that could be used to assess performance before conducting this procedure in the OR.

\section{Conflict of Interest Statement}

Authors have nothing to disclose with regard to commercial support. 
The authors thank the staff at the Steinberg Centre for Simulation and Interactive Learning for their support and technical assistance.

\section{References}

1. Mohr FW, Morice MC, Kappetein AP, Feldman TE, Ståhle E, Colombo A, et al. Coronary artery bypass graft surgery versus percutaneous coronary intervention in patients with three-vessel disease and left main coronary disease: 5-year follow-up of the randomized, clinical SYNTAX trial. Lancet. 2013;381:629-38.

2. Farkouh ME, Domanski M, Sleeper LA, Siami RS, Dangas G, Mack M, et al. Strategies for multivessel revascularization in patients with diabetes. $N$ Engl J Med. 2012;367:2375-84

3. Gulati R, Rihal CS, Gersh BJ. The SYNTAX Trial A perspective. Circ Cardiovasc Interv. 2009;2:463-7.

4. American College of Cardiology and American Heart Association Task Force. Guideline update for coronary artery bypass graft surgery. J Am Coll Cardiol. 2004; $44: 1146-54$

5. Hess CN, Lopes RD, Gibson CM, Hager R, Wojdyla DM, Englum BR, et al. Saphenous vein graft failure after coronary artery bypass surgery: insights from PREVENT IV. Circulation. 2014;130:1445-51.

6. Zenati MA, Shroyer AL, Collins JF, Hattler B, Ota T, Almassi GH, et al. Impact of endoscopic versus open saphenous vein harvest technique on late coronary artery bypass grafting patient outcomes in the ROOBY (Randomized On/Off Bypass) Trial. J Thorac Cardiovasc Surg. 2011;141:338-44.

7. Doty DB, Doty JR. Coronary artery bypass graft. In: Doty DB, Doty JR, eds. Cardiac Surgery: Operative Technique. 2nd ed. Philadelphia: Elsevier; 2012: 393-431.

8. Antonioli LC, Bennett HC. Vein harvesting for coronary artery bypass surgery. AORN J. 1994;59:969-79.

9. Delaria GA, Hunter JA, Goldin MD, Serry C, Javid H, Najafi H. Leg wound complications with coronary revascularization. J Thorac Cardiovase Surg. 1981;81:403-7.

10. Paletta CE, Huang DB, Fiore AC, Swartz MT, Rilloraza FL, Gardner JE. Major leg wound complications after saphenous vein harvest for coronary revascularization. Ann Thorac Surg. 2000;70:492-7.

11. Wipke-Tevis DD, Stotts NA, Skov P, Carrieri-Kohlman V. Frequency, manifestations, and correlates of impaired healing of saphenous vein harvest incisions. Heart Lung. 1996;25:108-16.

12. Davies J, Khatib M, Bello F. Open surgical simulation-a review. J Surg Educ. 2013;70:618-27.

13. Fonseca AL, Evans LV, Gusberg E. Open surgical simulation in residency training: a review of its status and a case for its incorporation. J Surg Educ. 2013;70:129-37.

14. Baker CJ, Sinha R, Sullivan ME. Development of a cardiac surgery simulation curriculum: from needs assessment results to practical implementation. J Thorac Cardiovasc Surg. 2012;144:7-16.

15. Pugh DM, Wood TJ, Boulet JR. Assessing procedural competence: validity considerations. Sim Healthcare. 2015;10:288-94.
16. Bandura A. Guide for constructing self-efficacy scales. In: Pajares F, Urdan T, eds. Self-Efficacy Beliefs of Adolescents, 5. Greenwich, CT: Information Age Publishing; 2006:307-37.

17. Martin JA, Regehr G, Reznick R, Macrae H, Murnaghan J, Hutchison C, et al Objective structured assessment of technical skill (OSATS) for surgical residents. Br J Surg. 1997;84:273-8.

18. Reznick R, Regehr G, MacRae H, Martin J, McCulloch W. Testing technical skill via an innovative "bench station" examination. Am J Surg. 1997:173:226-30.

19. MacRae H, Regehr G, Leadbetter W, Reznick RK. A comprehensive examination for senior surgical residents. Am J Surg. 2000;179:190-3.

20. Dath D, Regehr G, Birch D, Schlachta C, Poulin E, Mamazza J, et al Toward reliable operative assessment: the reliability and feasibility of videotaped assessment of laparoscopic technical skills. Surg Endosc. 2004;18: 1800-4.

21. Koo TK, Li MY. A guideline of selecting and reporting intraclass correlation coefficients for reliability research. J Chiropr Med. 2016;15:155-63.

22. Landers R. Computing intraclass correlations (ICC) as estimates of interrater reliability in SPSS. The Winnower. 2015;4:e143518.81744.

23. Chi MTH. Two approaches to the study of experts' characteristics. In: Ericsson KA, Charness N, Feltovich P, Hoffman R, eds. The Cambridge Handbook of Expertise and Expert Performance. New York: Cambridge University Press; 2006:121-30.

24. Fann JI, Caffarelli AD, Georgette G, Howard SK, Gaba DM, Youngblood P, et al Improvement in coronary anastomosis with cardiac surgery simulation. J Thorac Cardiovasc Surg. 2008;136:1486-91.

25. Joyce DL, Dhillon TS, Caffarelli AD, Joyce DD, Tsirigotis DN, Burdon TA, et al Simulation and skills training in mitral valve surgery. J Thorac Cardiovasc Surg. 2011;141:107-12.

26. Hance J, Aggarwal R, Stanbridge R, Blauth C, Munz Y, Darzi A, et al. Objective assessment of technical skills in cardiac surgery. Eur J Cardiothorac Surg. 2005 28:157-62.

27. Ito J, Shimamoto T, Sakaguchi G, Komiya T. Impact of novel off-pump coronary artery bypass simulator on the surgical training. Gen Thorac Cardiovasc Surg. 2013;61:270-3.

28. Greenhouse DG, Grossi EA, Dellis S, Park J, Yaffee DW, DeAnda A, et al. Assessment of a mitral valve replacement skills trainer: a simplified, low-cost approach. J Thorac Cardiovasc Surg. 2013;145:54-9.

29. Kozlowski SWJ, DeShon RP. A psychological fidelity approach to simulationbased training: theory, research, and principles. In: Salas E, Elliott LR, Schflett SG, Coovert MD, eds. Scaled Worlds: Development, Validation, and Applications. Burlington: Ashgate Publishing; 2004:75-99.

30. Scalese RJ, Obeso VT, Issenberg B. Simulation technology for skills training and competency assessment in medical education. J Gen Intern Med. 2004 23:46-9.

31. Fann JI, Feins RH, Hicks GK, Nesbitt JC, Hammon JW, Crawford FA, member of the Senior Tour in Cardiothoracic Surgery. Evaluation of simulation training in cardiothoracic surgery: the Senior Tour perspective. J Thorac Cardiovasc Surg. 2012;143:264-7.

Key Words: saphenous vein, surgical simulation, assessment 